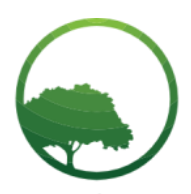

Research in Business \& Social Science

\title{
Analyzing the effect of financial reward, personal cost and reporting channel on whistleblowing intentions utilizing an experimental study
}

\author{
Ni Made Mega Abdi Utami $\oplus_{a}$, Gugus Irianto $\unrhd_{b}$, Yeney Widya Prihatiningtias $@_{c}$ \\ Crossref
}

a,b,cFaculty of Economics and Business, Brawijaya University, Malang, Indonesia

\author{
A RTICLE INFO \\ Article history: \\ Received 23 December 19 \\ Received in revised form 05 Feb 20 \\ Accepted 08 February 20 \\ Keywords: \\ Financial reward, Personal cost, \\ Reporting channel, Whistleblowing \\ intention. \\ JEL Classification: \\ C91, D73
}

\begin{abstract}
A B S T R A C T
This study aims to determine the effect of financial rewards (given and not given), personal costs (low and high) and reporting channels (anonymous and non-anonymous) on whistleblowing intentions. This study also analyzes the interaction effects among financial reward and personal cost, financial reward and reporting channel as well as personal cost and reporting channel on whistleblowing intentions. Participants in this study involve 65 finance and accounting employees of state universities in Bali. This research employs a $2 \times 2 \times 2$ experimental design. The results of this study indicate that whistleblowing intentions are greater when given financial rewards compared to not given financial rewards, in low personal cost compared with a high personal cost, reported through anonymous reporting channels than in non-anonymous reporting channels. The results of the interaction effect indicate that greater whistleblowing occurs when given a financial reward (case at a low personal cost), through non-anonymous reporting channels. The results also confirm that higher whistleblowing intentions appear in a low personal cost through anonym reporting channels.
\end{abstract}

(C) 2020 by the authors. Licensee BSC International Publishing, Istanbul, Turkey. This article is an open access article distributed under the terms and conditions of the Creative Commons Attribution (CC BY) license (http://creativecommons.org/licenses/by/4.0/).

\section{Introduction}

In ACFE Indonesia (2016) conducted a fraud survey in Indonesia, emphasizing that tipping contributed to higher fraud in Indonesia (37\%). Such finding postulated that whistleblowing serves as a good fraud detection method. On the other side, whistleblowing unfortunately causes a dilemma as people are discouraged from becoming whistleblowers due to the fear of retaliation. Based on the results of a survey conducted by IBE (2017), it was concluded that as many as $56 \%$ of employees who were aware of the fraud, choose to remain silent and to not report the fraud. Research conducted by James et al. (1995) stated that almost one-sixth whistleblowers who received negative consequences from their actions were reluctant to conduct any whistleblowing. However, whistleblowers (90\%) who did not receive negative consequences of their actions, mentioned about future possibility to commit whistleblowing. Relevant study has suggested that retaliation is believed to reduce whistleblowing intentions; even such effort could hamper fraud detection and eradication in Indonesia.

It has been common where regulators in developed and developing countries attempt to encourage whistleblowing intentions such as by giving rewards to whistleblowers (Andon et al., 2016). Albeit rewards have been enacted, there are still many people who are hesitant to do whistleblowing due to fear of the negative consequences. The personal cost of whistleblowing is important to be minimized in providing a sense of security for the doers, encouraging effective efforts to prevent and eradicate fraud. There are several types of reporting channels such as anonymous and non-anonymous reporting channels, in which each channel has unique strengths and weaknesses along with different possibilities in generating fraud reporting intentions (Ayers \& Kaplan, 2005).

Anonymous reporting channels encourage whistleblowing intentions due to lower personal costs (Kaplan \& Schultz, 2007). Nonanonymous reporting offers opportunities to improve reporting integrity and enable more effective reporting systems in enforcing any suspicious actions (Kaplan \& Schultz, 2007). Upon referring to such phenomenon, this study intends to determine the effect of financial rewards (given and not given), personal costs (low and high) and reporting channels (anonymous and non-anonymous) on

* Corresponding author. ORCID ID: 000-0003-1755-5646

(C) 2020 by the authors. Hosting by SSBFNET. Peer review under responsibility of Center for Strategic Studies in Business and Finance. https://doi.org/10.20525/ijrbs.v9i2.614 
whistleblowing intentions. This study will also analyze the interaction effects among financial reward and personal cost, financial reward and reporting channel and personal cost and reporting channel on whistleblowing intentions.

This paper presents the result of experimental study about the effect of financial reward, personal cost and reporting channels on whistleblowing intention. We find that whistleblowing intentions are greater when given financial, in low personal cost compared with high personal cost, reported through anonymous reporting channels than in non-anonymous reporting channels. The results of the interaction effect indicate that greater whistleblowing occurs when given a financial reward and at a low personal cost, whistleblowing intentions through non-anonymous reporting channels will be higher when given a financial reward. The results also confirm that higher whistleblowing intentions appear in a low personal cost through anonym reporting channels.

\section{Literature Review}

Several relevant theories such as Theory of Planned Behaviour, Prosocial Behaviour Theory and Utilitarian Theory highlight that someone will evaluate or assess whether the behavior is favorable in accordance with a motive to achieve personal gain. Other considerations lie on the social pressure to do or not do such behavior. Someone will evaluate the ease or difficulty encountered to conduct behavior and how someone can be convinced, whether the existing circumstances support or hinder the decided action. Therefore, a decision-maker is required to consider the impact or consequences of each alternative and to decide a more beneficial option for all concerned parties (Brief \& Motowildo, 1986; Dozier \& Micelli, 1985; Ajzen, 1991; Ajzen, 2002; Cavanagh et al., 1981).

\section{Financial reward and whistleblowing intention}

Prosocial Behavior Theory defines whistleblowing as an act that is not only based on altruism, but also on egoism. Altruism refers that whistleblowing is committed for the benefit of greater community. However, egoism emphasizes that whistleblowing at a certain level contains a motive to achieve personal gain (Dozier \& Miceli, 1985). Based on the explanation from the Prosocial Behavior Theory, providing financial rewards to whistleblowers is expected to encourage whistleblowing intentions. Previous researches on the effect of financial reward on whistleblowing intentions indicated that financial reward influenced whistleblowing intentions; or in other words, given financial rewards would encourage whistleblowing intentions (Andon et al., 2016; Schmolke \& Utikal,2016; Butler et al., 2017; and Xu \& Ziegenfuss, 2008). Based on this explanation, the hypothesis is:

H1: Whistleblowing will be greater, if given a financial reward compared to not given a financial reward.

\section{Personal cost and whistleblowing intention}

Theory of Planned Behavior explains personal cost in the subjective norm, where the social factors such as perceived social factor pressures in committing or not committing an action (Ajzen, 1991). Retaliation that will be received by whistleblowers is normally in a form of social pressure. The threat or fear of retaliation greatly reduces the intention of whistleblowing (Mesmer-magnus \& Viswesvaran, 2005). Personal cost is considered to hinder whistleblowing intentions, as proven by previous studies (Ayers \& Kaplan, 2005; Mesmer-magnus \& Viswesvaran, 2005; Alleyne et al., 2013; Boo et al., 2016). confirming that personal cost presents a negative effect on whistleblowing intentions. Based on this explanation, the hypothesis is:

$\mathrm{H} 2$ : Whistleblowing intention will be greater in low personal cost compared to high personal cost.

\section{Reporting channel and whistleblowing intention}

Planned Behavior Theory (perceived behavioral control) puts more highlights on explanation towards individual's decision in determining either anonymous or non-anonymous reporting channel. Perceived behavioral control refers to expectations regarding the extent to which an individual performs certain behaviors to overcome both internal and external obstacles (Ajzen, 2002). The referred inhibiting factor is the possibility of a threat of retaliation towards the whistleblower. Although there is a possibility of retaliation from reporting fraud, there is also a solution to eliminate personal cost by providing anonymous reporting channels, taken into consideration by individuals whether whistleblowing is committed. Anonymous reporting channels encourage whistleblowing intentions since personal costs are much lower when a whistleblower utilizes anonymous reporting channels than that in nonanonymous (Kaplan \& Schultz, 2007). Prior relevant studies on anonymous and non-anonymous reporting channels (Johansson \& Carey, 2016; Kaplan \& Schultz, 2007; Kaplan et al., 2012) pointed out that anonymous reporting channels influence whistleblowing intentions. Based on this explanation, the hypothesis is:

H3: Whistleblowing will be greater when reporting through the anonymous reporting channel.

\section{Financial reward, personal cost and whistleblowing intentions}

Theory of Planned Behavior explains that an individual takes an action based on several predictors, such as: attitude towards behavior and social factor called subjective norm. Attitude towards behavior marks the level at which an individual evaluates or assesses whether the behavior is favorable (Ajzen, 1991). Prosocial behavior theory also explains that an individual committing whistleblowing also has a motive to achieve personal gain (Dozier \& Miceli, 1985). The second predictor is a social factor called subjective norm, which refers to the perceived social pressure to do or to not do a behavior (Ajzen, 1991; Heungsik \& Blenkinsopp, 
2009). Individual will also consider the reactions of surrounding community when figuring out any whistleblowing deed. An apparent negative reaction such a threat of retaliation is believed to reduce whistleblowing intentions, which is in line with Abraham Maslow's hierarchy of needs theory postulating that everyone needs a sense of security. Research conducted by Guthrie \& Taylor (2017) clarified that whistleblowing intentions will be greater if the whistleblower is given financial rewards at low personal cost. Based on this explanation, the hypothesis is:

H4: Whistleblowing will be greater if given a financial reward and at a low personal cost

\section{Financial reward, reporting channel and whistleblowing intentions}

Theories of Planned Behavior and Prosocial Behavior signify that an individual will evaluate or assess whether the behavior is favorable due to a personal motive to achieve personal gain (Dozier \& Miceli, 1985; Ajzen, 1991). Financial rewards are expected to be a driving factor for increasing whistleblowing intentions. Another consideration for an individual committing a whistleblowing action is the obligation to consider the impact or consequences of each alternative deciding a more beneficial action for all concerned parties (Cavanagh et al., 1981). One of the considerations before conducting whistleblowing is to consider which reporting channels to conduct whistleblowing providing more benefits for all involved parties. Non-anonymous reporting channels provide benefit for organizations as it offers opportunities to improve reporting integrity and to enable more effective reporting systems in fraud detection and prevention (Kaplan \& Schultz, 2007). Non-anonymous reporting channels also benefit whistleblowers due to easier means in providing financial rewards. Research conducted by Pope \& Lee, 2012 pointed out that a financial reward encouraged an individual to report through a non-anonymous reporting channel. Based on this explanation, the hypothesis is:

H5: Whistleblowing will be greater if given financial rewards and through non-anonymous reporting channels.

\section{Personal cost, reporting channels and whistleblowing intentions}

Theory of Planned Behavior (perceived behavioral control) refers to an individual's perception of the ease or difficulty encountered to conduct a behavior due to supporting and inhibiting factors (Ajzen, 2002; Zakaria et al., 2016). The obstacles when committing whistleblowing, such as the threat of retaliation. Research conducted by Priyastiwi \& Halim (2018) states that employees will dare to report fraud that occurs in their work environment when they get support from their supervisor. Abraham Maslow's hierarchy of needs theory postulating that everyone needs a sense of security, anonymous reporting channels encourage whistleblowing intentions due to lower personal costs and give a sense of security (Kaplan \& Schultz, 2007). Prior study on the influence of personal costs and reporting channels was conducted by (Kaplan et al., 2012; Priyastiwi \& Halim, 2018), indicating that whistleblowing intentions will be higher if committed at low personal cost conditions through anonymous reporting channels. Based on this explanation, the hypothesis is:

H6: Whistleblowing intentions will be higher when at a low personal cost and through anonymous reporting channels.

\section{Research and Methodology}

This research applies a $2 \times 2 \times 2$ experimental design. Three independent variables (financial rewards, personal cost, reporting channels) will each be exposed to two treatments: financial reward (given and not given), personal cost (personal costs and no personal costs), and reporting channels (anonymous and non-anonymous). The assignment of participants in this experimental study is performed between-subject.

Table 1: Experiment group

\begin{tabular}{|c|c|c|c|c|}
\hline & Personal cost & & No person & \\
\hline & Anonym & Non-Anonym & Anonym & Non-Anonym \\
\hline Given financial reward & Grup 1 & Grup 3 & Grup 5 & Grup 7 \\
\hline $\begin{array}{l}\text { Not given financial } \\
\text { reward }\end{array}$ & Grup 2 & Grup 4 & Grup 6 & Grup 8 \\
\hline
\end{tabular}

\section{Participant}

This research was conducted at state universities in Bali. The participants of this experiment include all employees (65) of the finance and accounting department of State Universities in Bali.

\section{Manipulation}

There are two types of manipulation in the financial reward (given and not given), based on the regulation concerning a financial reward when reporting fraud and based on the regulation concerning no financial reward when reporting fraud. There are two types of manipulation in personal cost variables (high personal cost and low personal cost), which are mutation (for the reporter in high 
personal cost) and support from supervisor (for the reporter in low personal cost). The treatment of anonymous reporting channel is normally presented in the form of reporting by excluding the reporter identity. In contrast, the treatment of non-anonymous reporting channel in reporting includes the reporter identity.

\section{Experiment procedure}

The procedure of determining the group for each participant is accomplished by employing random assignment method, randomly dividing the participants into eight groups through the draw. The random assignment procedure in this study includes participants (who will be collected at their respective workplaces), in which the draw is created based on total number of participants and number of formed groups. Each lottery will be numbered as one to eight, which indicates the number of the group where the participants will be placed. Upon obtaining the lottery number, the participants are presented with a scenario (based on selected group), where each group receives a different experimental treatment; participants answer the questions in scenario by giving check-marks.

\section{Data Analysis Technique}

ANOVA (analysis of variance) is used to test the hypothesis specifically the main and interaction effect.

\section{Results and Discussions}

The results of the hypothesis test are presented below.

Table 2: Result of hypotesis one test

\begin{tabular}{lllllll}
\hline Financial Reward & N & Mean & SD & F hit & Sig. & Desc \\
\cline { 1 - 5 } Given & 33 & 5.682 & 1.006 & 19.786 & 0.000 & Significant \\
\cline { 1 - 4 } Not Given & 32 & 4.938 & 0.619 & & \\
\cline { 1 - 5 } Total & 65 & 5.315 & 0.912 & & \\
\hline
\end{tabular}

\section{Financial reward and whistleblowing intention}

The comparison result of the treatment in financial reward, indicate a significance value of 0,000 or smaller than 0.05 , concluding significant differences among the treatments on financial reward variables. The average value indicates that the whistleblowing intention is greater if given a financial reward compared to not given a financial reward. The results of this study are relevant with the Prosocial Behavior Theory explaining that prior to committing whistleblowing; an individual will consider the benefits due to personal motive (Chiu, 2002). The provision of financial rewards indicates that the organization appreciates the reported information about fraud encouraging an individual to committ whistleblowing (Taylor \& Guthrie, 2015). The results of this study also support previous studies (Pope \& Lee, 2012; Brink et al., 2013; Berger et al., 2017; Feldmen \& Lobel, 2010), indicating whistleblowing will be greater, if given a financial reward compared to not given a financial reward.

\section{Personal cost and whistleblowing intention}

The results of the hypothesis test are presented below.

Table 3: Result of Hypotesis Two Test

\begin{tabular}{lllllll}
\hline Personal Cost & N & Mean & SD & F hit & Sig. & Desc \\
\cline { 1 - 4 } High & 33 & 4.849 & 0.775 & 22.802 & 0.000 & Significant \\
\cline { 1 - 4 } Low & 32 & 5.797 & 0.792 & & \\
\cline { 1 - 4 } Total & 65 & 5.315 & 0.912 & & \\
\hline
\end{tabular}

The comparison results of treatments on personal cost indicate a significance value of $0,000(\mathrm{p}<0.05)$, marking significant differences among treatments on personal cost variables. The average value among treatments demonstrates that whistleblowing intention will be greater at a low personal cost compared with a high personal cost. Thus, the results of this test support Planned Behavior Theory (subjective norm) related to normative belief concerning an individual perception towards views of others when committing whistleblowing. Individual will consider whether the action is approved thanks to personal motivation to meet the expectations of others (Zakaria et al., 2016). Individuals experiencing negative social pressure (such as the threat of retaliation by committing whistleblowing) are reluctant due to disadvantageous social pressure. The results of this study are in accordance with previous studies (Guthrie \& Taylor, 2017; Alleyne et al., 2017; Latan et al., 2017; Alleyne et al, 2013; Hwang et al, 2008), pointing out that whistleblowing intention will be greater in low personal cost compared to high personal cost 


\section{Reporting channel and whistleblowing intention}

The results of the hypothesis test are presented below.

Table 4: Result of hypothesis three test

\begin{tabular}{|c|c|c|c|c|c|c|}
\hline Reporting Channel & $\mathbf{N}$ & Mean & SD & F hit & Sig. & Desc \\
\hline Anonymous & 38 & 5.118 & 0.919 & 4.261 & 0.043 & Significant \\
\hline Non-Anonymous & 27 & 5.593 & 0.844 & & & \\
\hline Total & 65 & 5.315 & 0.912 & & & \\
\hline
\end{tabular}

The comparison results of treatment for reporting channel indicate an average value among treatments emphasizing that whistleblowing intention would be greater through anonymous reporting channels. The significance value $(0.043)$ which is smaller than 0.05 , indicates significant differences among treatments in reporting channel.

Planned Behavior Theory (Perceived behavioral control and Utilitarian Theory) states that an individual will evaluate the importance of control to do whistleblowing such as perceived ease and difficulty or how opportunities or obstacles in committing whistleblowing. One also needs to calculate the consequences of each choice to decide more beneficial action for all entitled parties (Zakaria et al., 2016; Cavanagh et al., 1981).

Consideration of inhibiting factors such as the possibility of retaliation reduces whistleblowing intentions. The availability of anonymous reporting channels is regarded to negate personal costs as it excludes the identity of the reporter. The existence of anonymous reporting channels is not only beneficial for the whistleblower but also for the organization because it can streamline the implemented whistleblowing system. Thus, the results of this study support previous studies (Pope \& Lee, 2012; F et al., 2012; Nickolan et al., 2018; Johansson \& Carey, 2016), emphasizing that Whistleblowing will be greater when reporting through the anonymous reporting channel.

\section{Financial reward, personal cost and whistleblowing intention}

The results of the hypothesis test are presented below.

Table 5: Result of hypothesis four test

\begin{tabular}{lllllll}
\hline Financial Reward & Personal Cost & N & Mean & SD & F hit & Sig. \\
\cline { 1 - 4 } Given & High & 15 & 5.000 & 0.964 & 5.842 & 0.019 \\
\cline { 2 - 5 } & Low & 18 & 6.250 & 0.624 & \\
\hline Not Given & High & 18 & 4.722 & 0.575 \\
\cline { 2 - 4 } & Low & 14 & 5.214 & 0.579 &
\end{tabular}

The comparison results of the average value in the interaction of financial reward and personal cost variables confirm that whistleblowing intentions will be greater if given financial rewards at low personal cost conditions.

The significance value of 0.019 ( $\mathrm{p}<0.05)$ indicates significant differences among treatments in the interaction of financial reward and personal cost variables. The results of this study are in line with Prosocial Behavior Theory and Planned Behavior Theory, suggesting that an individual will consider the benefits that will be obtained as well as the costs related to the trust and reaction of people (social pressure) in the organization when doing or not doing a certain behavior (Rhodes \& Courneya, 2003).

Individuals will evaluate the benefits and costs of each option. Whistleblowing only occurs if individuals believe that the benefits of reporting outweigh personal costs (Hooks et al., 1994). The results of this study are also relevant with previous studies (Taylor \& Guthrie, 2015; Buccirossi et al., 2017; Guthrie \& Taylor, 2017) demonstrating that greater whistleblowing intentions occurs when given financial rewards at low personal cost conditions.

The provision of financial rewards and protection for whistleblowers must be equally strong. Providing financial rewards will not be effective if not accompanied by strong protection against threats due to the need for a guarantee of security, which encourages whistleblowing intentions and effective whistleblowing system.

\section{Financial reward, reporting channel and whistleblowing intention}


The results of the hypothesis test are presented below.

Table 6: Result of Hypothesis Five Test

\begin{tabular}{llccccc}
\hline Financial Reward & Reporting Channel & N & Mean & SD & F hit & Sig. \\
\hline Given & Anonymous & 18 & 5.333 & 1.098 & 5.777 & 0.019 \\
\cline { 2 - 5 } & Non-Anonymous & 15 & 6.100 & 0.712 & \\
\hline Not Given & Anonymous & 20 & 4.925 & 0.693 & \\
\cline { 2 - 5 } & Non-Anonymous & 12 & 4.958 & 0.498 & \\
\hline
\end{tabular}

The comparison results of treatments on the interaction of financial reward variables and reporting channels indicate a significance value of 0.019 ( $\mathrm{p}<0.05)$, marking significant differences among the treatments on the interaction of financial reward variables and reporting channels. Description of the average value demonstrates results that greater whistleblowing intention occurs when given financial rewards through non-anonymous reporting channels. The results of this study support Prosocial Behavior Theory, Theory of Planned Behavior and Utilitarian Theory pointing out that an individual takes action based on several considerations such as if someone will judge whether the behavior is beneficial to be done. Benefits of whistleblowing for whistleblowers include providing financial rewards, career advancement, and recognition (Robertson et al., 2011). Individuals must also consider the consequences of each choice and determine beneficial action for all parties (Cavanagh et al., 1981).

If financial rewards are available, reporters are more likely to reveal their identities rather than remain anonymous (Pope \& Lee, 2012). Similar results are also found in previous studies (Brink et al., 2013; Xu \& Ziegenfuss, 2008). The availability of nonanonymous reporting channels in whistleblowers exists due to easier provision of financial rewards because non-anonymous reporting channels require reporters to include their identity. This reporting channel also provides benefits for the organization to quickly investigate the report and immediately gather up information from the reporter.

\section{Personal cost, reporting channel and whistleblowing intention}

The results of the hypothesis test are presented below.

Table 7: Result of hypothesis six test

\begin{tabular}{lllllll}
\hline Personal Cost & Reporting Channel & N & Mean & SD & F hit & Sig. \\
\hline High & Anonymous & 21 & 4.548 & 0.631 & 10.300 & 0.002 \\
\cline { 2 - 5 } & Non-Anonymous & 12 & 5.375 & 0.742 & & \\
\hline Low & Anonymous & 17 & 5.824 & 0.706 & \\
\cline { 2 - 5 } & Non-Anonymous & 15 & 5.767 & 0.904 & \\
\hline
\end{tabular}

The comparison results of treatments on the interaction of personal cost and reporting channels depict a significance value of 0.002 ( $\mathrm{p}<0.05$ ), assuming significant differences among treatments on the interaction of personal cost and reporting channels. Meanwhile, the description of the average value indicates that higher whistleblowing intention occurs at a low personal cost through anonymous reporting channels. The results of this study support Planned Behavior Theory in subjective norm and perceived behavioral control. Subjective norms relate to referents and motivation to comply, in which an individual believes that the referent does approve of himself carrying out a behavior, then the individual will consider the social pressure by doing so (Ajzen, 2005 ).

Individuals tend to commit a behavior after evaluating the possibility of social pressure, the circumstances and opportunities in performing a decided behavior (Ajzen, 2005; Bobek \& Hatfield, 2003). Individuals are likely to select specific method minimizing the obstacles when doing whistleblowing such as the threat of retaliation. Anonymous reporting channels encourage whistleblowing intentions due to the lower personal cost through anonymous reporting channels by excluding reporter's identity and it will give a sense of security. Therefore, the results of this study also support previous studies (Priyastiwi \& Halim, 2018), emphasizing that Whistleblowing intentions will be higher when at a low personal cost and through anonymous reporting channels.

\section{Conclusions}

To conclude, greater whistleblowing intentions occur when given financial rewards compared to not given financial rewards. In addition, greater whistleblowing intention appears mostly in low personal cost compared with high personal cost. Last to point out, whistleblowing intentions will also be greater when reporting through anonymous reporting channels than through non-anonymous reporting channels when given a financial reward at a low personal cost through non-anonymous reporting channels. The results of this study are expected to contribute the decision-makers in state universities for providing financial rewards to increase whistleblowing intentions. The results of this study also provide input for state universities to anticipate preventive actions and to 
protect whistleblower from threats, along with proper decision for appropriate reporting channels at state universities in sustaining effective whistleblowing system.

\section{References}

ACFE. (2016). Report to the nation 2016 global study on occupational fraud and abuse global fraud study. Retrieved from https://www.acfe.com/rttn-2016/schemes/occupational.aspx.

Ajzen, I. (1991). The theory of planned behavior. organizational behavior and human decision processes 50, 179-211.doi: https://doi.org/10.1016/0749-5978(91)90020-T.

Ajzen, I. (2002). Perceived Behavioral Control, self-efficacy, locus of control, and the theory of planned behavior. Journal of Applied Social Psychology, 32(4), 665-683.doi: http://dx.doi.org/10.1111/j.1559-1816.2002.tb00236.x

Ajzen, I. (2005). Laws of human behavior: symmetry, compatibility, and attitude behavior correspondence. in a. Beauducel, B. Biehl, M. Bosniak, W. Conrad, G. Schonberger, \& D. Wagener (Eds.), Multivariate Research Strategies. Aachen, Germany: Shaker Verlag.

Alleyne, P., Hudaib, M., \& Pike, R. (2013). Towards a conceptual model of whistleblowing intentions among external auditors. The British Accounting Review, 45(1), 10-23. doi: http://dx.doi.org/10.1016/j.bar.2012.12.003.

Alleyne, P., Charles-Soveral, W., Broome, T., \& Pierce, A. (2017). Perception, Predictor and Consequence of Whistleblowing Among Accounting Employee in Barbados. Meditari Accounting Research, 25(2). 241-267.

Andon, P., Free, C., Jidin, R., Monroe, G. S., \& Turner, M.J. (2016). The Impact of Financial Incentives and Perceptions of Seriousness on Whistleblowing Intention. Journal of Business Ethics, 151(1), 165-178. doi: https://doi.org/10.1007/s10551016-3215-6.

Ayers, S., \& Kaplan, S. E. (2005). Wrongdoing by Consultants: An Examination of Employees' Reporting Intentions. Journal of Business Ethics, 57(2), 121-137. doi: 10.1007/s10551-004-4600-0.

Berger, L., Perreault, S., \& Wainberg, J. (2017). Hijacking the Moral Imperative: How Financial Incentives Can Discourage Whistleblower Reporting. Auditing: A Journal of Practice \& Theory, 36(3), 1-14. doi/10.2308/ajpt-51663.

Bobek, D. D., \& Hatfield, R. C. (2003). An Investigation of The Theory Of Planned Behavior and The Role Of Moral Obligation In Tax Compliance. Behavioral Research in Accounting, 15(1), 13-38.

Boo, E., Ng, T. B. P., \& Shankar, P. G. (2016) Effects of Incentive Scheme and Working Relationship on Whistle-Blowing in an Audit Setting. Auditing: A Journal of Practice \& Theory, 35(4), 23-38. doi: https://doi.org/10.2308/ajpt-51485.

Brief, A. P., \& Motowidlo, S. J. (1986). Prosocial Organizational Behaviors. Academy of Management Review, 11(4), 710-725. doi: $10.2307 / 258391$

Brink, A. G., Jordan Lowe, D., \& Victoravich, L. M. (2013) The Effect of Evidence Strength and Internal Rewards on Intentions to Report Fraud in the Dodd-Frank Regulatory Environment. Auditing: A Journal of Practice \& Theory, 32(3), 87-104. doi/10.2308/ajpt-50449.

Buccirossi, P., Immordino, G., \& Spagnolo, G. (2017). Whistleblower Reward, False Report and Corporate Fraud. Stockholm Institute of Transition Economics Working Paper No. 42. Doi: http://dx.doi.org/10.2139/ssrn.2993776

Butler, J. V., Serra, D., \& Spagnolo, G. (2017). Motivating Whistleblowers. CEIS Tor Vergata Research Paper Series, $15(9)$, 419. doi: $10.2139 / \mathrm{ssrn} .3086671$.

Cavanagh, G. F., Moberg, D. J., \& Velasquez, M. (1981). The Ethics of Organizational Politics. Academy of Management Review, 6(3). 363-374. doi: 10.2307/257372.

Chiu, R. K. (2002). Ethical Judgement, Locus of Control, and Whistleblowing Intention: A Case Study of Mainland Chinese MBA Students. Managerial Auditing Journal, 17(9), 581-587. doi: 10.1108/02686900210447588.

Dozier, J.B., \& Miceli, M. P. (1985). Potential Predictor of Whistle-Blowing: A Prosocial Behaviour Perspective. Academy of Management Review, 10(4), 823-836. doi: 10.2307/258050.

Guthrie, C. P., \& Taylor, E. Z. (2017). Whistleblowing on Fraud for Pay: Can I Trust You?. Journal of Forensic Accounting Research, 2(1), A1-A19. doi: doi/10.2308/jfar-51723.

Guthrie, C.P., Norman, C. S., \& Rose, J.M. (2012). Chief Audit Executives' Evaluations of Whistle-Blowing Allegations. Behavioral Research in Accounting, 24(2), 87-99. https://doi.org/10.2308/bria-50154.

Feldmen, Y., \& Lobel, O. (2010). The Incentives Matrix: The Comparative Effectiveness of Rewards, Liabilities, Duties, and Protections for Reporting Illegality. Texas Law Review, 88(6), 1151-1211.

Heungsik, P., \& Blenkinsopp, J. (2009). Whistleblowing as Planned Behavior - A Survey of South Korean Police Officers. Journal of Business Ethics, 85(4), 545-556. Doi: 10.1007/s10551-008-9788-y.

Hooks, K. L., Kaplan, S. E., \& Schultz, J. J., Jr. (1994). Enhancing communication to assist in fraud prevention and detection. Auditing: A Journal of Practice \& Theory, 13(2), 86-117.

Hwang, D., Staley, B., Te Chen, Y. \& Lan, J. (2008), Confucian Culture and Whistleblowing by Professional Accountants: An Exploratory Study, Managerial Auditing Journal,23(5), 504-526. doi:https://doi.org/10.1108/02686900810875316.

IBE. (2017). Survey on Business $2017 . \quad$ Retrieved from https://www.ibe.org.uk/userassets/briefings/2017_ibe_surveys_briefing.pdf.

James, S. L., Ardini, M. E., \& Matheson, J. L. (1995). Consequences of Whistleblowing for the Whistleblower in Misconduct in Science Cases. Retrived From https://ori.hhs.gov/sites/default/files/consequences_0.pdf. 
Johansson, E., \& Carey, P. (2016). Detecting Fraud: The Role of the Anonymous Reporting Channel. Journal of Business Ethics, 139(2), 391-409. doi: 10.1007/s10551-015-2673-6.

Kaplan, S. E., \& Schultz, J. J. (2007). Intentions to Report Questionable Acts: An Examination of the Influence of Anonymous Reporting Channel, Internal Audit Quality, and Setting. Journal of Business Ethics, 71(2), 109-124. doi:10.1007/s10551006-0021-6.

Kaplan, S. E., Pany, K., Samuels, J., \& Zhang, J. (2012). An Examination of Anonymous and Non-Anonymous Fraud Reporting Channels. Advances in Accounting, Incorporating Advances in International Accounting, 28(1), 88-95. doi:10.1016/j.adiac.2012.02.008.

Latan, H., Ringle, C. M., \& Jabbour, C. J. C. (2017). Whistleblowing Intention Among Public Accountant in Indonesia: Testing the Moderation Effect. Journal of Business Ethic (in Press).

Mesmer-Magnus, J. R., \& Viswesvaran, C. (2005). Whistleblowing in Organization: An Examination of Correlates of Whistleblowing Intention, Action and Retaliation. Journal of Business Ethics, 62(3), 277-297. doi: 10.1007/s10551-0050849-1.

Nickolan, F., Handajani, L., \& Hermanto. (2018). Whistleblowing Intention of Indonesian Government Internal Auditor (Apip) and Anonymous Reporting Channel Interactions. International Journal of Economic, Commerce and Management United Kingdom, 4(2). 161-175.

Pope, K. R., \& Lee, C. (2012). Could The Dodd-Frank Wall Street Reform and Consumer Protection Act Of 2010 Be Helpful In Reforming Corporate America? An Investigation on Financial Bounties and Whistle-Blowing Behaviors In The Private Sector. Journal of Business Ethics, 112(4), 597-607. doi : 10.1007/s10551-012-1560-7.

Priyastiwi., \& Halim, A. (2018). The Influence of Supervisor's Support and Protection Against Whistleblowing Decision in The Organizations of Local Government In Indonesia. The Indonesian Journal of Accounting Research, 21(3), 291-320. doi: 10.33312/ijar.362.

Rhodes, R. E., \& Courneya, K. S. (2003). Investigating Multiple Components Of Attitude, Subjective Norm, And Perceived Control: An Examination Of The Theory Of Planned Behavior In The Exercise Domain. British Journal of Social Psychology, 42(1), 129- 146. Doi: doi/abs/10.1348/014466603763276162.

Robertson, J. C., Stefaniak, C.M., \& Curtis, M. B. (2011) Does Wrongdoer Reputation Matter? Impact of Auditor-Wrongdoer Performance and Likeability Reputations on Fellow Auditors' Intention to Take Action and Choice of Reporting Outlet. Behavioral. Research in Accounting,23(2), 207-234. doi:10.2308/bria-50022.

Schmolke, K. U., \& Utikal, V. (2016). Whistleblowing: Incentives and Situational Determinants. FAU- Discussion Papers in Economics, 9. doi: dx.doi.org/10.2139/ssrn.2820475.

Taylor, E. Z., \& Guthrie, C. P. (2015). Protect or Pay? Promoting Internal Whistleblowing. Forensic Accounting Conference, At Denver Co. doi: 10.13140/2.1.2573.9047.

Xu. Y, \& Ziegenfuss, D. E. (2008). Reward Systems, Moral Reasoning, and Internal Auditors' Reporting Wrongdoing. Journal of Business and Psychology, 22(4), 323-331. doi: 10.1007/s10869-008-9072-2.

Zakaria, M., Razak, S. N. A., \& Yusoff, M. S. A. (2016). The Theory of Planned Behaviour as a Framework for Whistle-Blowing Intentions. Review of European Studies, 8(3). https://www.doi.org/10.5539/res.v8n3p221. 